\title{
Correction to: Radiation exposure for the surgical team in a hybrid-operating room
}

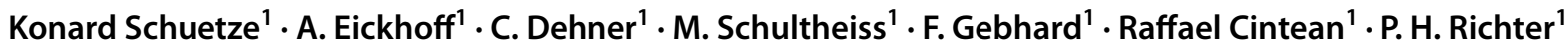

Published online: 18 July 2021

๑) Springer-Verlag London Ltd., part of Springer Nature 2021

Correction to: Journal of Robotic Surgery (2019) 13:91-98

https://doi.org/10.1007/s11701-018-0821-6

The original version of this article unfortunately contained a mistake. Raffael Cintean was not listed among the authors.

The correct author group should be: Konard Schuetze - A. Eickhoff $\cdot$ C. Dehner · M. Schultheiss · F. Gebhard · Raffael Cintean P. H. Richter.

Publisher's Note Springer Nature remains neutral with regard to jurisdictional claims in published maps and institutional affiliations.

The original article can be found online at https://doi.org/10.1007/ s11701-018-0821-6.

Konard Schuetze

konrad.schuetze@uniklinik-ulm.de

1 Department of Trauma-, Hand- and Reconstructive Surgery,

Ulm University, Albert-Einstein-Allee 23, 89081 Ulm,

Germany 